\title{
Functionalized regio-regular linear polyethylenes from the ROMP of 3-substituted cyclooctenes
}

\author{
Henry Martinez $\cdot$ Jihua Zhang $\cdot$ Shingo Kobayashi • \\ Yuewen Xu • Louis M. Pitet • Megan E. Matta • \\ Marc A. Hillmyer
}

Received: 27 January 2014/ Accepted: 31 January 2014/Published online: 25 February 2014

(C) The Author(s) 2014. This article is published with open access at Springerlink.com

\begin{abstract}
We demonstrated that the ring-opening metathesis polymerization (ROMP) of 3-substituted cyclooctenes bearing polar substituents allows the synthesis of highly regio- and stereo-regular polymers. A series of polyalkenamers with $90-99 \%$ head-to-tail/trans configuration were synthetized in good yields (33-87\% yield). Upon saturation of the backbone using diimide, these polymers represent a class of linear polyethylene derivatives where the polar side chain is located on every eighth carbon. The thermal properties of both the saturated and unsaturated polymers depend strongly on the size and polarity of the functional side groups. The results presented here demonstrate that the 3 -substituted cyclooctenes can be used not only for the synthesis of precisely functionalized polyethylene derivatives, but also to participate in the ringopening metathesis copolymerization with unfunctionalized cyclic olefins to generate copolymers with tunable properties.
\end{abstract}

Keywords ROMP · Polyethylene $\cdot$ Substituted polyolefin · Metathesis

Electronic supplementary material The online version of this article (doi:10.1007/s13203-014-0048-z) contains supplementary material, which is available to authorized users.

H. Martinez $\cdot$ J. Zhang $\cdot$ S. Kobayashi $\cdot$ Y. Xu

L. M. Pitet - M. E. Matta - M. A. Hillmyer $(\bowtie)$

Department of Chemistry, University of Minnesota, 207 Pleasant

St. SE, Minneapolis, MN 55455-0431, USA

e-mail: hillmyer@umn.edu

\section{Introduction}

Polyethylene (PE) is one of the most common plastics, the derivatives of which have found themselves useful in a variety of applications [1-3]. Incorporation of side chains, especially polar functional side chains, is desirable and often necessary to give the polymer desired properties and better performance. Due to the physical and chemical stability of $\mathrm{PE}$, direct functionalization of $\mathrm{PE}$ is challenging [4]. Therefore, PE derivatives bearing functional side chains are typically produced by radical or coordination copolymerization of ethylene and functionalized olefin(s). These polymerizations, however, frequently suffer from dramatically different comonomer reaction rates, intolerance of catalyst to polar functional groups and lack of control of polymer microstructure. As a consequence, controlling the scope, content and distribution of functional side chains in the polymer is undermined. A number of methods have been developed to overcome these problems, and notable examples include development of compatible catalysts [5, 6] and metathesis polymerization of functionalized monomers. The latter method is interesting because of catalyst compatibility to polar functional groups and, more attractively, potential to precisely control the polymer structure. Wagener and coworkers have utilized acyclic diene metathesis polymerization (ADMET) [7] of functionalized $\alpha, \omega$-dienes to prepare linear PE derivatives bearing a broad range of polar functional groups [8-29]. Many of the ADMET-derived polymers feature precisely placed polar side chains when a symmetric monomer is used. As opposed to the condensation polymerization nature of ADMET, ring-opening metathesis polymerization (ROMP) is an addition polymerization which requires less demanding conditions and allows better control of the polymer molar mass [30]. The use of functionalized cyclic 


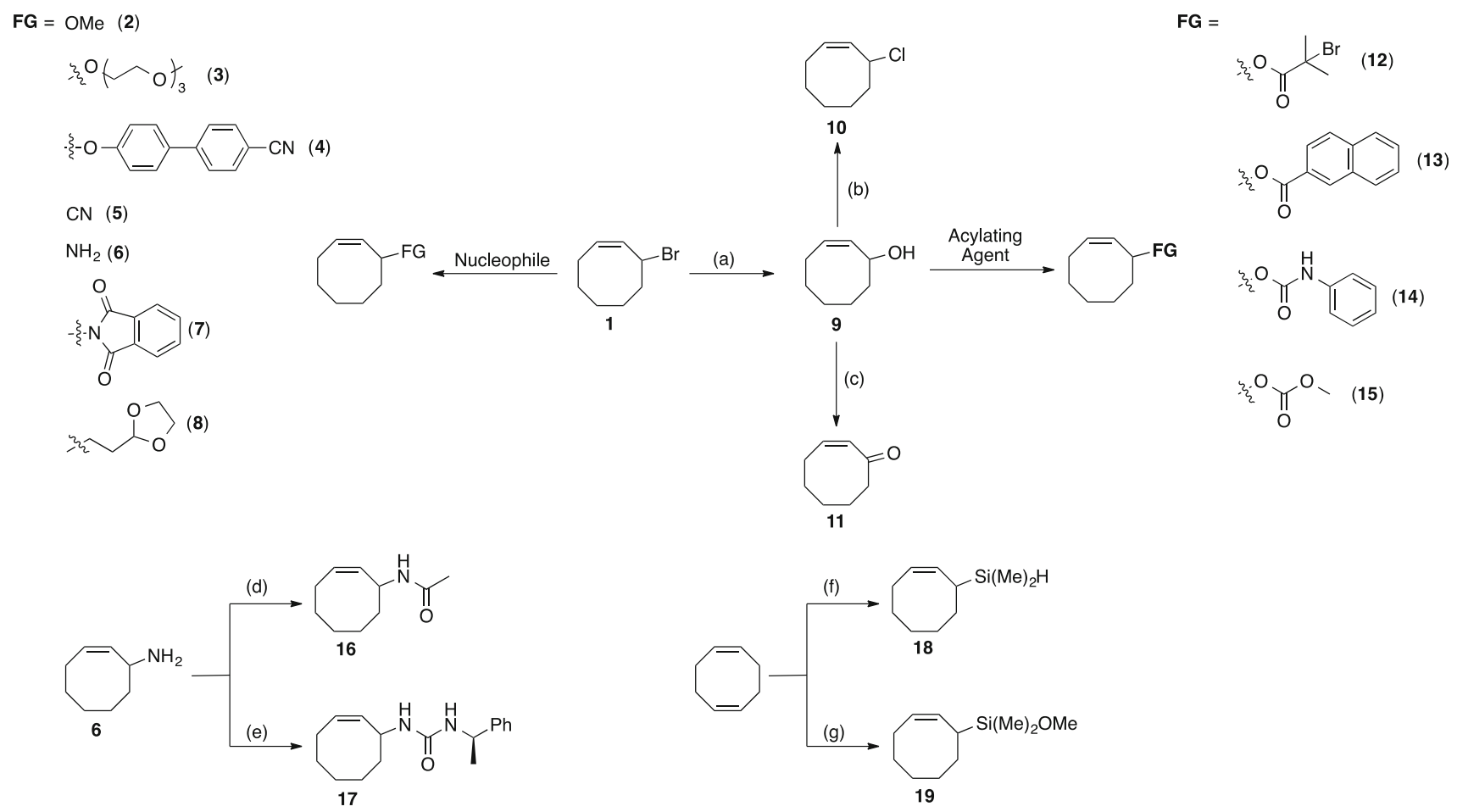

Scheme 1 Synthesis of various 3-substituted COEs. (a) Acetone/ water, $\mathrm{NaHCO}_{3}$, reflux 1 h. (b) $\mathrm{SOCl}_{2}$, Py. (c) Pyridinium chlorochromate, $\mathrm{CH}_{2} \mathrm{Cl}_{2}$. (d) $\mathrm{Et}_{3} \mathrm{~N} / \mathrm{AcCOCl}, \mathrm{CH}_{2} \mathrm{Cl}_{2}$. (e) DMAP,

olefins in ROMP has also been explored by many research groups to access to linear PE derivatives with diverse polar side chains, including boranes, thioethers, halides, nitrile, hydroxyl, carbonyl, esters, amides, urethanes and liquid crystal moieties [31-54]. However, excluding those in which the monomer is symmetrically substituted, only few examples resulted in regio-regular products [46, 48].

We recently published a series of reports [55-59] demonstrating that single substitution at the 3-position (i.e., the allylic position) of cis-cyclooctene (COE) was an effective way to synthesize regio- and stereo-regular polyalkenamers by ROMP using the well-defined Grubbs second (G2) or third (G3) generation catalysts. Such substituents we have explored included hydrocarbon groups (3RCOE, R = methyl, ethyl, hexyl or phenyl) $[55,56]$ and the acetoxy group [57-59]. All the reported polyalkenamers possess high levels (>95\%) of head-to-tail (HT) repeating unit connectivity and $E$ double bond configuration. Hydrogenation of these polymers afforded PE derivatives with precisely positioned branches, which exhibit distinct physical properties compared to their random counterparts. More importantly, these reports suggest that ROMP of any COE substituted with a sufficiently bulky group at the 3-position could proceed in a regio- and stereo-selective manner, which in combination with the exceptional functional group tolerance of Ru-based isocyanate. (f) 1. $\mathrm{H}_{2} \mathrm{PtCl}_{6} \cdot 6 \mathrm{H}_{2} \mathrm{O}, \mathrm{ClSiMe}_{2} \mathrm{H}, \mathrm{Cy}, 2$. LAH, THF. (g) $1 . \mathrm{H}_{2} \mathrm{PtCl}_{6} \cdot 6 \mathrm{H}_{2} \mathrm{O}, \mathrm{ClSiMe}_{2} \mathrm{H}, \mathrm{Cy}, 2 . \mathrm{MeOH}, \mathrm{Py}$

catalysts allows us to conveniently synthesize diversely functionalized precision PE derivatives.

In the present study, we explore the scope of polar functional groups that, when placed at the 3-position (3FGCOE, Scheme 1), are amenable to controlled ROMP with Ru-based catalysts. The polymer regio-regularity [head-to-tail (HT), head-to-head (HH) and tail-to-tail (TT)] and stereo-regularity (cis and trans) were analyzed in this study. These polymers, after the backbone is saturated, represent a class of linear PE derivatives where the polar side chain is located on every eighth carbon. The precision microstructure further enables investigation of the effect of side chain size and polarity on the polymer properties.

\section{Results and discussion}

Monomer synthesis

3-bromocyclooctene (1) was chosen as the principal starting material because of its scalable and highly efficient preparation. Several synthetic pathways were explored as shown in Scheme 1. The bromo group exhibited a wide range of reactivity towards the hydroxyl group in alcohols and phenol derivatives (compounds 2-4). Stirring compound $\mathbf{1}$ in anhydrous methanol at room temperature 
afforded 3-methoxy-COE (2) in $24 \mathrm{~h}$; and elevated temperature and extended reaction time was required to obtain compound $\mathbf{3}$ from its respective alcohol. However, no reaction of 1 with more hindered alcohols (e.g., secondary alcohols) or their deprotonated forms was observed, even after months. The phenoxide anion derived from phenol 4'hydroxy-4-biphenylcarbonitrile, which is a liquid crystal building block, reacts readily with $\mathbf{1}$ in DMF to give 3-substituted COE with an aryl ether group (compound 4). Other types of nucleophiles, including cyanide, ammonia, phthalimide and a Grignard reagent, reacted with $\mathbf{1}$ to generate the corresponding 3FGCOEs (compounds 5-7). 3-amino-COE (6) was used to synthesize 3FGCOE having amide (16) or urea (17) groups substituted at the 3-position (Scheme 1).

Treatment of 3-hydroxy-COE (9) [59] with thionyl chloride in the presence of pyridine gave 3-chloro-COE (10). The hydroxyl group in 9 was also oxidized to give 2-cyclooctenone (11). Furthermore, a variety of ester or urethane groups were introduced through the hydroxyl group by acylation or reaction with isocyanate (3FGCOE 12-15).

Two silicon-containing monomers (18 and 19) were synthetized from hydrosilylation of cis-1,5-cyclooctadiene followed by nucleophilic attack of hydride or methanol to replace the chloride atom. The hydrosilylation at the 3 position was expected if taken into account that the isomerization of cyclic dienes from non-conjugated to conjugated dienes has been previously reported using $\mathrm{H}_{2} \mathrm{PtCl}_{6}$ [60]. Based on NMR $<5 \%$ of 5-substituted COE monomer was obtained using this method.

\section{Polymer synthesis and characterization}

The compatibility of these 3FGCOEs with $\mathbf{G 2}$ and the capability of these functional groups to give regio- and stereo-selective polymerizations were tested in ROMP under various conditions (Scheme 2) and the results are summarized in Table 1. To have a fair basis to compare the reactivity of these monomers, all polymerizations were carried out at the same temperature $\left(60{ }^{\circ} \mathrm{C}\right)$ with comparable initial monomer concentration (1-2 M). Some 3FGCOEs with highly polar functional groups $(4,7,16$ and 17) were essentially insoluble in $\mathrm{CHCl}_{3}$ at the prescribed concentration; a co-solvent was employed in these cases to give a homogeneous solution. We attempted to use cis-4-octene as a chain transfer agent (CTA) to regulate the polymer molar mass as demonstrated in previous studies [55]. However, this effort only succeeded with some monomers while the others required higher catalyst loading to give polymers, suggesting these particular polar functional groups may inhibit the activity of $\mathbf{G 2}$.

Polymerization of ether-functionalized monomers $\mathbf{2}$ and $\mathbf{3}$ and carbonate monomer $\mathbf{1 5}$ under standard conditions resulted in polyalkenamers with the highest yields $(87,85$ and $88 \%$, respectively) among all the monomers in this study. Polymerization and isolation of these polymers were straightforward. In contrast, polymerization of monomers 8 and 13 under standard conditions resulted in reaction mixtures containing considerable quantities of residual monomer, even after $24 \mathrm{~h}$ of reaction, suggesting a lower reactivity of such monomers under the chosen conditions. Initial attempts to polymerize monomer $\mathbf{1 1}$ yielded insoluble gels upon precipitation in methanol. However, the polymerization proceeded successfully in the presence of butylated hydroxytoluene (BHT). Additional BHT was added to a solution of the dissolved polymer immediately after precipitation to avoid subsequent cross-linking. Monomers bearing a cyclic imide (7), urethane (14) or aryl-cyanide group (4) were successfully polymerized, but required a relatively high catalyst loading.

Three N-containing monomers, $\mathbf{6 , 1 6}$ and $\mathbf{1 7}$, as well as nitrile monomer $\mathbf{5}$, did not generate any polymer using $\mathbf{G 2}$ or the more reactive G3. In all cases, the reaction mixture turned a brown color within a few minutes, suggesting deactivation of the Ru catalyst. The failure of $\mathbf{5}$ or $\mathbf{6}$ was not surprising, as compounds containing nitrile groups or primary amines are known to deactivate the Ru catalysts [33, 36, 37, 61, 62]. However, the monomers bearing acetamide (16) and urea (17) functional groups did not polymerize either. Some studies suggested that amides and ureas were compatible with the $\mathrm{Ru}$ catalysts in both polymerizations [49-51] and small molecule reactions [63]. The reason for the inactivity in our trials is unknown.

The two Si-containing monomers, 18 and 19, did not polymerize even at high catalyst loading. In both cases, the reaction mixture remained a yellow color even after $24 \mathrm{~h}$, suggesting that the catalyst was active. Addition of $\mathrm{COE}$ after $24 \mathrm{~h}$ to both reaction mixtures yielded poly(COE) only in the solution that contained monomer 19, which not

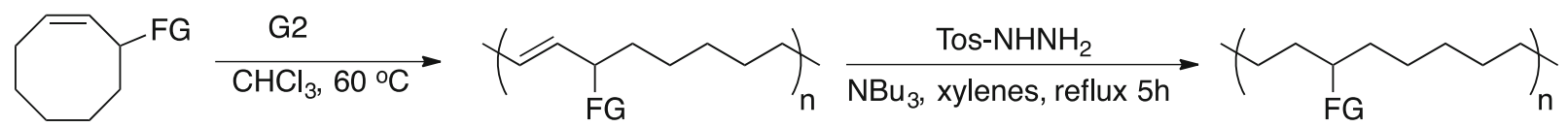

11 Polar functional groups (FG)

$33-87 \%$ yield $>90 \%$ trans-HT
$>85 \%$ yield

Scheme 2 Synthesis of linear polyethylene derivatives via ROMP followed by hydrogenation 
Table 1 Polymers from ROMP of various 3FGCOEs bearing polar functional groups using G2 $^{\mathrm{a}}$

\begin{tabular}{|c|c|c|c|c|c|c|c|c|c|}
\hline \multirow[t]{2}{*}{ 3FGCOE } & \multirow[t]{2}{*}[\mathrm{G}2]{$^{\mathrm{a}}(\mathrm{mol} \%)$} & \multirow[t]{2}{*}[\mathrm{CTA}]{$^{\mathrm{a}}(\mathrm{mol} \%)$} & \multirow[t]{2}{*}{ Conv. $^{\mathrm{b}}(\%)$} & \multirow[t]{2}{*}{ Yield $^{\mathrm{c}}(\%)$} & \multicolumn{2}{|c|}{$M_{\mathrm{n}}(\mathrm{kg} / \mathrm{mol})$} & \multirow[t]{2}{*}{$\oplus^{\mathrm{e}}$} & \multirow[t]{2}{*}{$E-\mathrm{HT}^{\mathrm{f}}(\%)$} & \multirow{2}{*}{$\begin{array}{l}T_{\mathrm{g}}^{\mathrm{g}} \\
\left({ }^{\circ} \mathrm{C}\right)\end{array}$} \\
\hline & & & & & $\mathrm{Cal}^{\mathrm{d}}$ & $\overline{\text { SEC }^{\mathrm{e}}}$ & & & \\
\hline $1^{\mathrm{h}}$ & 0.20 & N/A & - & 69 & - & - & - & - & - \\
\hline 2 & 0.04 & 1.0 & $>99$ & 87 & 13.5 & 29.0 & 1.8 & 95 & -54 \\
\hline 3 & 0.10 & 1.0 & $>99$ & 85 & 21.0 & 33.6 & 2.5 & 90 & -69 \\
\hline $4^{i}$ & 0.10 & N/A & 89 & 33 & 270 & 258 & 2.0 & 96 & 32 \\
\hline $7^{j}$ & 0.10 & N/A & 98 & 71 & 250 & 240 & 1.4 & $>99$ & 58 \\
\hline 8 & 0.025 & 1.0 & 91 & 64 & 18.7 & 26.0 & 1.5 & 98 & -34 \\
\hline $10^{\mathrm{h}}$ & 0.2 & N/A & - & 81 & - & - & - & - & - \\
\hline $11^{\mathrm{k}}$ & 0.025 & 1.0 & 92 & 73 & 12.1 & 27.6 & 1.7 & $>99$ & -26 \\
\hline 13 & 0.025 & 1.0 & 66 & 42 & 18.1 & 15.3 & 2.0 & $>99$ & 2 \\
\hline 14 & 0.2 & N/A & 82 & 66 & 101 & 121 & 1.7 & 92 & 37 \\
\hline 15 & 0.025 & 1.0 & $>99$ & 88 & 18.0 & 38.3 & 1.9 & 97 & -28 \\
\hline
\end{tabular}

All polymerizations conducted at $60{ }^{\circ} \mathrm{C}$ with initial monomer concentration of $1-2 \mathrm{M}$ in $\mathrm{CHCl}_{3}$ if not otherwise stated

${ }^{\text {a }}$ Relative to monomer concentration, CTA $=$ cis-4-octene

${ }^{b}$ Determined by ${ }^{1} \mathrm{H}$ NMR analysis of the reaction mixture

c Isolated yield

${ }^{\mathrm{d}} M_{\mathrm{n}}(\mathrm{cal})=\mathrm{MW}($ monomer $) \times$ Conv. $\times[M]_{0} /([\mathrm{G} 2]+[\mathrm{CTA}])$

${ }^{\text {e }}$ Determined by $\mathrm{SEC}$ in $\mathrm{CHCl}_{3}$ at $30{ }^{\circ} \mathrm{C}$ versus polystyrene standards

${ }^{\mathrm{f}}$ Estimated by ${ }^{1} \mathrm{H}$ NMR of the isolated polymer in $\mathrm{CDCl}_{3}$

g Determined by DSC (2nd heating cycle) at $10{ }^{\circ} \mathrm{C} \mathrm{min}{ }^{-1}$

h At room temperature

i $1: 1(\mathrm{v} / \mathrm{v}) \mathrm{CHCl}_{3}:$ toluene

j $3: 1(\mathrm{v} / \mathrm{v}) \mathrm{CHCl}_{3}: \mathrm{THF}$

${ }^{\mathrm{k}}$ This polymer showed a $T_{\mathrm{m}}$ at $106{ }^{\circ} \mathrm{C}\left(\Delta H=64 \mathrm{~J} \mathrm{~g}^{-1}\right)$

only suggested that the catalyst was active, but also that the $\mathrm{SiMe}_{2} \mathrm{OMe}$ group in position 3 of the COE is bulky enough to inhibit the catalyst approach to the double bond. The fact that $\mathrm{COE}$ did not polymerize in the solution that contained monomer 18 might be due to oxidative addition of the $\mathrm{Si}-\mathrm{H}$ group to the Ru center. Similar reactions have been used to perform hydrosilylation on terminal alkynes using Grubbs' first generation catalyst (G1) or G2 catalyst [64, 65].

Both 3-hydroxy-COE (9) and 3- $\alpha$-bromoisobutyrateCOE (12) [66] monomers quickly gave insoluble gels, indicating the formation of physically cross-linked networks possibly through strong hydrogen bonding (9) or covalent bonds (12) among polymer chains.

Polymers obtained from the halide-containing monomers (1 and 10) decomposed easily during the polymerization, generating dark insoluble rubbery materials. This result was not observed during the ROMP of 5-chloro or 5-bromo substituted COE [33-35], which suggests polymers of $\mathbf{1}$ and $\mathbf{1 0}$ are prone to halide elimination to generate conjugated dienes, possibly facilitated by the $\mathrm{Ru}$ catalyst.

Qualitatively, different rates of polymerization were observed with these 3FGCOEs, most of which gave polymers in high or quantitative conversion. However, significantly lower conversions were obtained with
3FGCOEs bearing aryl groups (4 and 13). This result is consistent with that reported on 3-phenyl COE, suggesting that bulky and rigid substituents result in lower polymerization rate. The polymer number average molar mass $\left(M_{\mathrm{n}}\right)$ determined by size exclusion chromatography (SEC) compared with polystyrene standards and the corresponding theoretical value were only in good agreement for the polymers containing aryl groups. This phenomenon can be attributed to the systematic difference of hydrodynamic radius between the polymer and the polystyrene standard, which is likely smaller in structurally similar polymers. The molar mass dispersity $(\nexists)$ ranged from 1.4 to 2.5 , in accordance with the typical values for products from ROMP with extensive cross-metathesis.

The regio- and stereo-regularity of poly(3FGCOE) samples was characterized by ${ }^{1} \mathrm{H}$ and ${ }^{13} \mathrm{C}$ NMR spectroscopy (see spectra in SI). Results comparable to those reported for our original poly(3RCOE) [55, 59] samples were observed for every poly(3FGCOE), namely high content of head-totail (HT) structure and $E$ double bond configuration (Table 1). This result confirms our hypothesis that sufficiently bulky substituent at the 3-position gives rise to regioand stereo-selective polymerization [55-59]. Thermal characterization using differential scanning calorimetry 
Table 2 Characterization of hydrogenated polymers

\begin{tabular}{lllllll}
\hline & $\begin{array}{l}\text { Yield }^{\mathrm{a}} \\
(\%)\end{array}$ & $\begin{array}{l}M_{\mathrm{n}}^{\mathrm{b}} \\
\left(\mathrm{kg} \mathrm{mol}^{-1}\right)\end{array}$ & $D^{\mathrm{b}}$ & $\begin{array}{l}T_{\mathrm{g}}^{\mathrm{c}} \\
\left({ }^{\circ} \mathrm{C}\right)\end{array}$ & $\begin{array}{l}T_{\mathrm{m}}^{\mathrm{c}} \\
\left({ }^{\circ} \mathrm{C}\right)\end{array}$ & $\begin{array}{l}\Delta H_{\mathrm{m}}^{\mathrm{c}} \\
\left(\mathrm{J} \mathrm{g}^{-1}\right)\end{array}$ \\
\hline PH2 & 80 & 36.8 & 1.6 & -70 & $15^{\mathrm{d}}$ & 25 \\
PH3 & 85 & 34.1 & 1.9 & -74 & -5 & 25 \\
PH7 & 90 & 38.3 & 4.1 & 37 & - & - \\
PH8 & 92 & 24.9 & 1.6 & -49 & - & - \\
PH13 & 60 & 17.0 & 1.8 & 18 & - & - \\
PH14 & 77 & 57.6 & 3.4 & 51 & - & - \\
PH15 & 83 & 49.4 & 2.1 & -32 & 49 & 0.4 \\
\hline
\end{tabular}

${ }^{a}$ Isolated yield

b Determined by SEC in $\mathrm{CHCl}_{3}$ at $30^{\circ} \mathrm{C}$ versus polystyrene standards

c Determined by DSC (2nd heating cycle) at $10^{\circ} \mathrm{C} \mathrm{min}^{-1}$

${ }^{\mathrm{d}}$ Cold crystallization at $-38{ }^{\circ} \mathrm{C}\left(\Delta H=25 \mathrm{~J} \mathrm{~g}^{-1}\right)$

(DSC) suggested nearly all poly(3FGCOE) are amorphous with glass transition temperatures $\left(T_{\mathrm{g}}\right)$ in the range of -69 to $58{ }^{\circ} \mathrm{C}$ (Table 1 ). The $T_{\mathrm{g}}$ of these polyalkenamers vary substantially (from -69 to $58{ }^{\circ} \mathrm{C}$ ) and are clearly dependent on the functional group identity. Poly(3FGCOE) with relatively small and less polar functional groups (e.g., P2) consistently exhibit lower $T_{\mathrm{g}}$ than those with relatively bulky and more polar functional groups (e.g., P7). Interestingly, P11 showed a $T_{\mathrm{m}}$ at $106{ }^{\circ} \mathrm{C}\left(\Delta H=64 \mathrm{~J} \mathrm{~g}^{-1}\right)$. When compared with the regio-irregular poly(cyclooct-4-enone) reported by Hillmyer et al. [33] in 1995 via ROMP using a Ru-based catalyst, P11 has a higher $T_{\mathrm{g}}\left(-58 \mathrm{vs} .-26^{\circ} \mathrm{C}\right)$ and $T_{\mathrm{m}}\left(34\right.$ vs. $\left.106{ }^{\circ} \mathrm{C}\right)$. This is consistent with the fact that at higher regio- and stereo-regularity both $T_{\mathrm{g}}$ and $T_{\mathrm{m}}$ increases $[55,59]$. Similarly, the polymer microstructure has been shown to have profound influence on the thermal properties in precision polyethylenes prepared by ADMET [67].

Chemical hydrogenation of polyalkenamers using diimide has shown to be an effective way to generate saturated backbone [68]. We applied this method to hydrogenate poly(3FGCOE), which resulted in a polymer equivalent to a copolymer of one part functionalized alpha olefin and three parts ethylene. With the exception of P4 and P11, the corresponding hydrogenated polymers were obtained in decent yields (Table 2). P4 has poor solubility in xylenes, while P11 cross-linked while heating the solution of xylenes (even in the presence of large amounts of BHT) resulting in an insoluble gel. NMR analysis revealed the presence of the expected functional group in the expected content in the hydrogenated polymers (see SI), suggesting the reaction conditions are compatible with these functional groups. The clean and well-defined ${ }^{13} \mathrm{C}$ NMR spectra further support the regio-regular structure in the hydrogenated polymers as well as in their unsaturated precursors. With the exception of P7 and P14, SEC in
$\mathrm{CHCl}_{3}$ versus polystyrene standard showed slight increase of molar mass and comparable dispersity for all hydrogenated polymers. Hydrogenated polymers of P7 and P14 (PH7 and PH14, respectively) exhibited a large decrease in apparent molar mass and much broader dispersity compared to the unsaturated precursors. Considering that no noticeable change of functional group was observed in NMR spectra, we assume that the change of molar mass and dispersity may be due solely to conformational changes (i.e., hydrodynamic radius) of the hydrogenated polymers in $\mathrm{CHCl}_{3}$. However, we cannot rule out some level of chain scission.

Table 2 summarizes the thermal characterization using DSC of the hydrogenated polymers. PH7, PH8, PH13 and PH14, where the functional group is bulky, remained amorphous. The $T_{\mathrm{g}}$ of the saturated polymers range from -74 to $51{ }^{\circ} \mathrm{C}$, and dependent on the functional group. Similarly to the unsaturated polymers, small substituents exhibit a much lower $T_{\mathrm{g}}$ than those with relatively bulky substituents. In addition to a glass transition, both $\mathrm{PH} 2$ and PH3 displayed well-defined melting transition transitions and PH15 showed a small but unambiguous melting peak, indicating that these polymers are semi-crystalline. PH3 with the larger substituent (PEG) showed a lower melting point than that in PH2 or PH15 with the smaller substituents (OMe and OCOMe, respectively). The only report of a 5-methoxy-COE polymerized via ROMP with a Ru-based catalyst does not report thermal properties for such polymer [69]. We previously reported that the saturated polymer of 3-methyl-COE (poly(3MeCOE)) exhibited a $T_{\mathrm{g}}$ at $-59{ }^{\circ} \mathrm{C}$, a $T_{\mathrm{m}}=2{ }^{\circ} \mathrm{C}$ and $\Delta H_{\mathrm{m}}=30 \mathrm{~J} \mathrm{~g}^{-1}$ [55]. When the $T_{\mathrm{m}}$ of poly(3MeCOE) is compared with that of PH2 and PH15, the more polar polymers (PH2 and PH15) show a higher $T_{\mathrm{m}}$ despite being larger groups; however, the $\Delta H_{\mathrm{m}}$ was lower in both cases. The more polar PH3, despite having the largest of all substituents, shows a $T_{\mathrm{m}}$ with equal enthalpy of melting to that of $\mathrm{PH} 2$. These results indicate that the polarity of the substituent and that of the polymer has a strong influence in the final thermal properties of the polymer. The polarity appears to have greater effect on crystallization than does the size; this could possibly be due to the polar functional group strengthening inter-chain interaction and thus favoring crystallization.

\section{Conclusions}

In summary, we demonstrated an efficient pathway to rapidly expand the scope of 3-substituted COE bearing diverse polar functional groups (3FGCOEs). Many of these 3FGCOEs allow ROMP using the Grubbs Ru-based catalyst (G2) to afford functionalized polyalkenamers, which possess HT regio-regularity and E-stereo-regularity. Both 
poly(3FGCOE) and the saturated poly(3FGCOE) exhibit thermal properties dependent on the size and polarity of the functional groups. This methodology, complementary to the ADMET approach, can be utilized to prepare PE derivatives with diverse polar side chains, including but not limited to those described in this study, which are difficult to be synthesized through radical or coordination copolymerization. Some examples demonstrated here further enable the incorporation of functional groups that are problematic with typical ROMP catalysts and conditions. For instance, PH7 can be properly treated to release free amine side or PH8 can be use to generate free aldehyde groups. It is envisioned that 3FGCOEs would be used not only to synthesize precision functionalized PE derivatives but also to participate in the ring-opening metathesis copolymerization with unfunctionalized cyclic olefins. These advances are a step forward to new graft copolymers $[66,70]$ and complex supramolecular structures with PE backbone.

Acknowledgments We thank the Abu Dhabi-Minnesota Institute for Research Excellence (ADMIRE) and Dow Chemical Company for support.

Open Access This article is distributed under the terms of the Creative Commons Attribution License which permits any use, distribution, and reproduction in any medium, provided the original author(s) and the source are credited.

\section{References}

1. Peacock A (2000) Handbook of polyethylene: structures: properties, and applications, 1st edn. CRC Press, FL

2. Fink JK (2010) Handbook of engineering and specialty thermoplastics: polyolefins and styrenics. Scrivener Publishing LLC, USA

3. Cordeiro CF, Petrocelli FP (2004) Encyclopedia of polymer science and technology. Wiley-VCH, Weinheim

4. Boaen NK, Hillmyer MA (2005) Post-polymerization functionalization of polyolefins. Chem Soc Rev 34:267-275

5. Boffa LS, Novak BM (2000) Copolymerization of polar monomers with olefins using transition-metal complexes. Chem Rev 100:1479-1494

6. Nakamura A, Ito S, Nozaki K (2009) Coordination-insertion copolymerization of fundamental polar monomers. Chem Rev 109:5215-5244

7. Baughman TW, Wagener KB (2005) Recent advances in ADMET polymerization. Adv Polym Sci 176:1-42

8. Valenti DJ, Wagener KB (1998) Direct synthesis of well-defined alcohol-functionalized polymers via acyclic diene metathesis (ADMET) polymerization. Macromolecules 31:2764-2773

9. Watson MD, Wagener KB (2000) Ethylene/vinyl acetate copolymers via acyclic diene metathesis polymerization. Examining the effect of "long" precise ethylene run lengths. Macromolecules 33:5411-5417

10. Watson MD, Wagener KB (2000) Functionalized polyethylene via acyclic diene metathesis polymerization: effect of precise placement of functional groups. Macromolecules 33:8963-8970
11. Hopkins TE, Pawlow JH, Koren DL, Deters KS, Solivan SM, Davis JA, Gomez FJ, Wagener KB (2001) Chiral polyolefins bearing amino acids. Macromolecules 34:7920-7922

12. Hopkins TE, Wagener KB (2003) Amino acid and dipeptide functionalized polyolefins. Macromolecules 36:2206-2214

13. Baughman TW, van der Aa E, Lehman SE, Wagener KB (2005) Circumventing the reactivity ratio dilemma: synthesis of ethylene-co-methyl vinyl ether copolymer. Macromolecules 38:2550-2551

14. Baughman TW, van der Aa E, Wagener KB (2006) Linear ethylene-vinyl ether copolymers: synthesis and thermal characterization. Macromolecules 39:7015-7021

15. Boz E, Wagener KB, Ghosal A, Fu RQ, Alamo RG (2006) Synthesis and crystallization of precision ADMET polyolefins containing halogens. Macromolecules 39:4437-4447

16. Baughman TW, Chan CD, Winey KI, Wagener KB (2007) Synthesis and morphology of well-defined poly(ethylene-coacrylic acid) copolymers. Macromolecules 40:6564-6571

17. Berda EB, Lande RE, Wagener KB (2007) Precisely defined amphiphilic graft copolymers. Macromolecules 40:8547-8552

18. Boz E, Wagener KB (2007) Progress in the development of welldefined ethylene-vinyl halide polymers. Polym Rev 47:511-541

19. Berda EB, Wagener KB (2008) Inducing pendant group interactions in precision polyolefins: synthesis and thermal behavior. Macromolecules 41:5116-5122

20. Boz E, Ghiviriga I, Nemeth AJ, Jeon K, Alamo RG, Wagener KB (2008) Random, defect-free ethylene/vinyl halide model copolymers via condensation polymerization. Macromolecules 41:25-30

21. Opper KL, Fassbender B, Brunklaus G, Spiess HW, Wagener KB (2009) Polyethylene functionalized with precisely spaced phosphonic acid groups. Macromolecules 42:4407-4409

22. Opper KL, Wagener KB (2009) Precision sulfonic acid ester copolymers. Macromol Rapid Commun 30:915-919

23. Mei JG, Aitken BS, Graham KR, Wagener KB, Reynolds JR (2010) Regioregular electroactive polyolefins with precisely sequenced $\pi$-conjugated chromophores. Macromolecules 43:5909-5913

24. Aitken BS, Lee M, Hunley MT, Gibson HW, Wagener KB (2010) Synthesis of precision ionic polyolefins derived from ionic liquids. Macromolecules 43:1699-1701

25. Opper KL, Markova D, Klapper M, Mullen K, Wagener KB (2010) Precision phosphonic acid functionalized polyolefin architectures. Macromolecules 43:3690-3698

26. Aitken BS, Wieruszewski PM, Graham KR, Reynolds JR, Wagener KB (2012) Control of charge-carrier mobility via in-chain spacer length variation in sequenced triarylamine functionalized polyolefins. ACS Macro Lett 1:324-327

27. Aitken BS, Wieruszewski PM, Graham KR, Reynolds JR, Wagener KB (2012) Perfectly regioregular electroactive polyolefins: impact of inter-chromophore distance on PLED EQE. Macromolecules 45:705-712

28. Aitken BS, Buitrago CF, Heffley JD, Lee M, Gibson HW, Winey KI, Wagener KB (2012) Precision ionomers: synthesis and thermal/mechanical characterization. Macromolecules 45:681-687

29. Leonard JK, Wei YY, Wagener KB (2012) Synthesis and thermal characterization of precision poly(ethylene-co-vinyl amine) copolymers. Macromolecules 45:671-680

30. Bielawski CW, Grubbs RH (2007) Living ring-opening metathesis polymerization. Prog Polym Sci 32:1-29

31. Ramakrishnan S, Chung TC (1990) Poly(5-hydroxyoctenylene) and its derivatives: synthesis via metathesis polymerization of an organoborane monomer. Macromolecules 23:4519-4524

32. Couturier JL, Tanaka K, Leconte M, Basset JM, Ollivier J (1993) Metathesis of sulfur-containing olefins with a metallacyclic 
aryloxo(chloro)neopentylidenetungsten complex. Angew Chem Int Ed 32:112-115

33. Hillmyer MA, Laredo WR, Grubbs RH (1995) Ring-opening metathesis polymerization of functionalized cyclooctenes by a ruthenium-based metathesis catalyst. Macromolecules 28:6311-6316

34. Yang HL, Islam M, Budde C, Rowan SJ (2003) Ring-opening metathesis polymerization as a route to controlled copolymers of ethylene and polar monomers: synthesis of ethylene-vinyl chloride-like copolymers. J Polym Sci Part A Polym Chem 41:2107-2116

35. Xu GJ, Wang DR, Buchmeiser MR (2012) Functional polyolefins: poly(ethylene)-graft-poly(tert-butyl acrylate) via atom transfer radical polymerization from a polybrominated alkane. Macromol Rapid Commun 33:75-79

36. Schneider MF, Gantner C, Obrecht W, Nuyken O (2010) Ringopening metathesis polymerization of nitrile substituted cis-cyclooctenes. Macromol Rapid Commun 31:1731-1735

37. Schneider MF, Gantner C, Obrecht W, Nuyken O (2011) Ringopening metathesis polymerization of cis-cyanocyclooct-4-ene: search for active catalysts, variation of monomer to catalyst ratios and monomer concentrations. J Polym Sci Part A Polym Chem 49:879-885

38. Scherman OA, Kim HM, Grubbs RH (2002) Synthesis of welldefined poly((vinyl alcohol)2-alt-methylene) via ring-opening metathesis polymerization. Macromolecules 35:5366-5371

39. Scherman OA, Walker R, Grubbs RH (2005) Synthesis and characterization of stereoregular ethylene-vinyl alcohol copolymers made by ring-opening metathesis polymerization. Macromolecules 38:9009-9014

40. Hejl A, Scherman OA, Grubbs RH (2005) Ring-opening metathesis polymerization of functionalized low-strain monomers with ruthenium-based catalysts. Macromolecules 38:7214-7218

41. Maughon BR, Grubbs RH (1996) Synthesis and controlled crosslinking of polymers derived from ring-opening metathesis polymerization (ROMP). Macromolecules 29:5765-5769

42. Breitenkamp K, Simeone J, Jin E, Emrick T (2002) Novel amphiphilic graft copolymers prepared by ring-opening metathesis polymerization of poly(ethylene glycol)-substituted cyclooctene macromonomers. Macromolecules 35:9249-9252

43. Breitenkamp K, Emrick T (2003) Novel polymer capsules from amphiphilic graft copolymers and cross-metathesis. J Am Chem Soc 125:12070-12071

44. Lehman SE, Wagener KB, Baugh LS, Rucker SP, Schulz DN, Varma-Nair M, Berluche E (2007) Linear copolymers of ethylene and polar vinyl monomers via olefin metathesis-hydrogenation: synthesis, characterization, and comparison to branched analogues. Macromolecules 40:2643-2656

45. Han HJ, Chen FX, Yu JH, Dang JY, Ma Z, Zhang YQ, Xie MR (2007) Ring-opening metathesis polymerization of functionalized cyclooctene by a ruthenium-based catalyst in ionic liquid. J Polym Sci Part A Polym Chem 45:3986-3993

46. Song AR, Parker KA, Sampson NS (2009) Synthesis of copolymers by alternating ROMP (AROMP). J Am Chem Soc 131:3444-3445

47. Kratz K, Breitenkamp K, Hule R, Pochan D, Emrick T (2009) PC-polyolefins: synthesis and assembly behavior in water. Macromolecules 42:3227-3229

48. Song AR, Lee JC, Parker KA, Sampson NS (2010) Scope of the ring-opening metathesis polymerization (ROMP) reaction of 1-substituted cyclobutenes. J Am Chem Soc 132:10513-10520

49. Breitenkamp RB, Ou Z, Breitenkamp K, Muthukumar M, Emrick $T$ (2007) Synthesis and characterization of polyolefin-graft-oligopeptide polyelectrolytes. Macromolecules 40:7617-7624

50. Revanur R, McCloskey B, Breitenkamp K, Freeman BD, Emrick $\mathrm{T}$ (2007) Reactive amphiphilic graft copolymer coatings applied to poly(vinylidene fluoride) ultrafiltration membranes. Macromolecules 40:3624-3630

51. Kobayashi S, Kim H, Macosko CW, Hillmyer MA (2013) Functionalized linear low-density polyethylene by ring-opening metathesis polymerization. Polym Chem 4:1193

52. Shi HC, Shi DA, Yin LG, Luan SF, Zhao J, Yin JH (2010) Synthesis of amphiphilic polycyclooctene-graft-poly(ethylene glycol) copolymers by ring-opening metathesis polymerization. React Funct Polym 70:449-455

53. Winkler B, Rehab A, Ungerank M, Stelzer F (1997) A novel sidechain liquid crystal polymer of 5-substituted cis-cyclooctene via ring-opening metathesis polymerization. Macromol Chem Phys 198:1417-1425

54. Xia Y, Verduzco R, Grubbs RH, Kornfield JA (2008) Welldefined liquid crystal gels from telechelic polymers. J Am Chem Soc 130:1735-1740

55. Kobayashi S, Pitet LM, Hillmyer MA (2011) Regio- and stereoselective ring-opening metathesis polymerization of 3-substituted cyclooctenes. J Am Chem Soc 133:5794-5797

56. Martinez H, Miró P, Charbonneau P, Hillmyer MA, Cramer CJ (2012) Selectivity in ring-opening metathesis polymerization of Z-cyclooctenes catalyzed by a second-generation Grubbs catalyst. ACS Catal 2:2547-2556

57. Zhang J, Matta ME, Hillmyer MA (2012) Synthesis of sequencespecific vinyl copolymers by regioselective ROMP of multiply substituted cyclooctenes. ACS Macro Lett 1:1383-1387

58. Pitet LM, Zhang J, Hillmyer MA (2013) Sequential ROMP of cyclooctenes as a route to linear polyethylene block copolymers. Dalton Trans 42:9079-9088

59. Zhang J, Matta ME, Martinez H, Hillmyer MA (2013) Precision vinyl acetate/ethylene (VAE) Copolymers by ROMP of acetoxysubstituted cyclic alkenes. Macromolecules 46:2535-2543

60. Benkeser RA, Mozdzen EC, Muench WC, Roche RT, Siklosi MP (1979) Organic chemistry of dichlorosilane. Additions to conjugated and unconjugated diene systems followed by intramolecular cyclizations. J Org Chem 44:1370-1376

61. Slugove C (2004) The ring opening metathesis polymerisation toolbox. Macromol Rapid Commun 25:1283-1297

62. Leitgeb A, Wappel J, Slugove C (2010) The ROMP toolbox upgraded. Polymer 51:2927-2946

63. Formentin P, Gimeno N, Steinke JHG, Vilar R (2005) Reactivity of Grubbs' catalysts with urea- and amide-substituted olefins. Metathesis and isomerization. J Org Chem 70:8235-8238

64. Menozzi C, Dalko PI, Cossy J (2005) Hydrosilylation of terminal alkynes with alkylidene ruthenium complexes and silanes. J Org Chem 70:10717-10719

65. Polshettiwar V, Varma RS (2008) Olefin ring closing metathesis and hydrosilylation reaction in aqueous medium by Grubbs second generation ruthenium catalyst. J Org Chem 73:7417-7419

66. Xu Y, Thurber CM, Lodge TP, Hillmyer MA (2012) Synthesis and remarkable efficacy of model polyethylene-graft-poly(methyl methacrylate) copolymers as compatibilizers in polyethylene/ poly(methyl methacrylate) blends. Macromolecules 45:9604-9610

67. Rojas G, Berda EB, Wagener KB (2008) Precision polyolefin structure: modeling polyethylene containing alkyl branches. Polymer 49:2985-2995

68. Hahn SF (1992) An improved method for the diimide hydrogenation of butadiene and isoprene containing polymers. J Polym Sci Part A Polym Chem 30:397-408

69. Demonceau A, Stumpf AW, Saive E, Noels AF (1997) Novel ruthenium-based catalyst systems for the ring-opening metathesis polymerization of low-strain cyclic olefins. Macromolecules 30:3127

70. Chung TC (2002) Synthesis of functional polyolefin copolymers with graft and block structures. Prog Polym Sci 27:39-85 